\title{
Optimal design of trapezoidal lined channel with least cost: Semi- theoretical approach powered by genetic programming
}

\author{
FA Tofiq ${ }^{1}$ and A Guven ${ }^{1 *}$ \\ 'Civil Engineering Department, University of Gaziantep, Üniversite Bulvarı, 27310, Gaziantep-Turkey
}

\begin{abstract}
In this paper the effects of the aspect ratio (width to depth ratio, $b / d$ ) on the cost of a trapezoidal concrete-lined channel (either power channel or irrigation channel) are analysed. The recommended b/d ratios given in the literature and their limitations are also discussed. Efforts are made to derive an equation for determining the optimal depth of the water from known parameters such as discharge, velocity and bed slope for concrete-lined channels. An equation for finding the minimum possible discharge within a specific velocity and bed slope is developed based on a semi-theoretical approach. The same approach is followed to obtain another formula for finding the maximum possible velocity for a specific discharge and bed slope. The obtained equations eliminate the iteration process commonly involved in finding the dimensions of a trapezoidal channel. A relation is developed for finding the aspect ratio in response to a given discharge and bed slope by using linear genetic programming techniques. The results show that the proposed model can be successfully applied in the design of lined channels as an alternative to existing methods.
\end{abstract}

Keywords: lined channel, power channel, irrigation, design, genetic programming

\section{INTRODUCTION}

In developing countries suffering from water scarcity, the conservation of water is vital, as demand for this natural resource continues to rise rapidly, and, simultaneously, new sources of supply become harder to find. In arid regions, water losses from unlined small field channels are usually high due to seepage and evaporation from open surfaces. These losses are often neglected by many project planners and engineers (Moghazi and Ismaeli, 1996). In developing countries, many sections within the length of open channels are unlined, which causes considerable water loss (Arshad et al., 2009). The rate of water loss depends on soil characteristics within the region of the project as well as on hydraulic parameters (wetted perimeter and hydraulic radius) and discharge parameters (velocity and cross-section). The benefits of lining irrigation channels with the aim to reduce these losses cannot be ignored. Channel lining plays an increasing role in preventing water loss and thus improving irrigation facilities (Monadjemi, 1994). A number of research studies have been undertaken toward optimal design of canal cross-sections and water saving in irrigation systems (Ghazaw et al., 2000; Swamee et al., 2000; Swamee et al., 2002; Ghazaw et al., 2011).

Since the lining will add extra cost to the project, the expenditure on a lining project should be justified when the resultant annual benefit exceeds the annual cost, including interest on capital investment. Adopting a lining project instead of continuing to use an existing unlined irrigation system has several advantages, such as reduction in the land occupied by the channel, saving in cost of earth works and auxiliary works, and other positive effects (Ghumman et al., 2012). For a lining project the savings from the previously mentioned benefits should be equal to or greater than the additional cost of lining. Hence, optimal design of a lined channel is of immense importance.

\footnotetext{
* To whom all correspondence should be addressed.

- +903172429, E-mail: aguven@gantep.edu.tr

Received 22 October 2014; accepted in revised form 4 June 2015
}

The following steps summarize the recommended procedure for determining the proportions of a lined channel section (Chow, 1959; French, 1986):

- (Step 1) Estimate Manning's coefficient $(n)$ and determine longitudinal slope $(S)$

- (Step 2) Compute the section factor:

$$
A R^{2 / 3}=\frac{n Q}{\sqrt{S}}
$$

where: $A$ is the cross-sectional area $\left(\mathrm{m}^{2}\right), R$ is the hydraulic radius $(\mathrm{m}), Q$ is the discharge $\left(\mathrm{m}^{3} / \mathrm{s}\right), S$ is the bed slope, and $n$ is the Manning's roughness coefficient $\left(\mathrm{s} / \mathrm{m}^{1 / 3}\right)$. Solve Eq. 1 for a given depth. In this step, width and side slope for trapezoidal sections may be assumed based on the type of the soil and topography, in order to find water depth.

- (Step 3) Check minimum and maximum permissible velocities

- (Step 4) Estimate free board value

Eq. 1 can be rearranged to be Eq. 2 and Eq. 3 as derived by Trout (1982)

$$
\begin{aligned}
& A R^{2 / 3}=\frac{A^{5 / 3}}{P^{2 / 3}}=\frac{\left(b d+z d^{2}\right)^{5 / 3}}{\left[b+2 d \sqrt{1+z^{2}}\right]^{2 / 3}}=\frac{n Q}{\sqrt{S}} \\
& d=\frac{\left[(b / d)+2 \sqrt{1+z^{2}}\right]^{1 / 4}}{[(b / d)+z]^{5 / 8}}\left(\frac{n Q}{\sqrt{S}}\right)^{3 / 8}
\end{aligned}
$$

where: $d$ is the depth of water (m), $b$ is the bed width of the channel (m) and $z$ is side slope. In order to solve Eq. 3, aspect ratio $(\mathrm{b} / \mathrm{d})$ should be assumed.

According to Subramanya (1986), the relationship between width and depth varies widely depending on the design practice. If the hydraulically most-efficient channel section is adopted, $z=1 / \sqrt{ } 3, b=2 d / \sqrt{ } 3, b / d=1.1547$. If any other values of $z$ are used the ratio would be as follows:

$$
\frac{b}{d}=2\left(\sqrt{1+z^{2}}-z\right)
$$

in which the aspect ratio depends totally on side slope $z$ (Guo and Hughes, 1984). 
The Central Water Commission (CWC), which is a technical organization in the field of water resources under the Ministry of Water Resources of the Government of India, recommend that the aspect ratio be considered as a function of discharge, as given in Table 1 (Subramanya, 1986).

As mentioned by Chow (1959), United States Bureau of Reclamation (USBR) proportioned channel section by empirical rules

$$
d=0.5 \sqrt{A}
$$

For a trapezoidal channel this can be expressed as follows (i.e. $b / d$ as a function of side slope).

$$
\frac{b}{d}=4-z
$$

According to Chow (1959), Indian engineers have also proportioned channel sections by another empirical rule:

$$
d=\sqrt{\frac{A}{3}}
$$

For trapezoidal sections this can be expressed as follows (i.e. $b / d$ as a function of side slope):

$$
\frac{b}{d}=3-z
$$

A similar cross-sectional function to Eq. 4 was adapted by Blackler and Guo (2009) and the following aspect ratio was introduced taking into consideration the cost factor:

$$
\frac{b}{d}=2(1-C)\left(\sqrt{1+z^{2}}-z\right)
$$

where: $C$ is the cost factor determined by channel lining cost to land cost ratio. This equation is not applicable in the case of having a ratio of 1 or more.

Trout (1982) noticed that the open channel cost optimization problem is analogous to the classic microeconomic problem of minimizing production costs through input substitution. In this case, the output of the system is the hydraulic capacity, whereas the inputs are the variables which define the channel geometry and the production function is the equation for the section factor. Based on this the aspect ratio for the optimum cross-section is as follows: (French, 1986; Trout, 1982)

$$
\frac{b}{d}=\frac{2 K_{1}}{-K_{2}+\left[K_{2}^{2}+20\left(\frac{B}{E}\right) K_{1}\right]^{1 / 2}}
$$

where:

$$
\begin{aligned}
& K_{1}=20\left(z^{2}+1\right)-\left[1+4\left(\frac{B}{E}\right)\right] 4 z \sqrt{z^{2}+1} \\
& K_{2}=\left(1-\frac{B}{E}\right) 6 \sqrt{z^{2}+1}-10 z\left(\frac{B}{E}\right)
\end{aligned}
$$

In these formulas $B$ is the cost of base lining material for a specified thickness per unit area; $E$ is the cost of side lining material for a specified thickness per unit area. The aspect ratio in Eq. 10 depends on the cost of lining for the sides and bed of the channel as well as the side slope. In these formulae, the excavation cost is not taken into consideration, unlike the case presented in this research. Minimum cost design of lined channels involves minimization of the sum of depth-dependant excavation cost and cost of lining (Swamee et al., 2000).

In this study, an attempt is made to develop a relationship between the aspect ratio and other factors, such as the discharge, bed slope, and velocity. In this approach, a semitheoretical approach is followed. This approach determines the optimal aspect ratio in lined trapezoidal channels based on maximum permissible velocity, minimum discharge criteria, using linear genetic programming techniques. The results from application of the proposed formulae, when compared to the results arising from the use of the conventional formulae commonly reported on in the literature, reveals that the proposed method can be successfully applied in the design of lined irrigation channels as a superior alternative to conventional options.

\section{METHODOLOGY}

\section{Analysis of relation between $b / d$ ratio and the cost of channel}

For analysing the effect of the aspect ratio $(b / d)$ on the cost of the cross-section, 12 cross-sections have been designed by usking the assumptions given in Table 2.

The continuity equation and Eq. 3 were used to find the dimensions of the channel cross-section. The cost per unit

\begin{tabular}{|l|c|c|c|c|c|c|}
\hline \multicolumn{7}{|c|}{ TABLE 1 } \\
Recommended aspect ratio (b/d) for different discharges (CWC) \\
\hline $\boldsymbol{Q}\left(\mathbf{m}^{3} / \mathrm{s}\right)$ & 0.3 & 3 & 14 & 28 & 140 & 285 \\
\hline $\boldsymbol{b} / \boldsymbol{d}$ & 2 & 4 & 6 & 7.5 & 14 & 18 \\
\hline
\end{tabular}

\begin{tabular}{|l|l|}
\hline \multicolumn{2}{|c|}{ TABLE 2} \\
\hline Item & Dessumed values of channel design parameters \\
\hline Discharge & $5,10,15,20,25$, and $30 \mathrm{~m}^{3} / \mathrm{s}$ \\
\hline Aspect ratio $(b / d)$ & 0.1 up to 1.8 with increasing interval of 0.1 \\
\hline Manning's coefficient (concrete) & 0.017 (Chin, 2006) \\
\hline Bed slope & 0.002 and 0.001 \\
\hline Side slope $(z)$ & $1.5 \mathrm{H}: 1.0 \mathrm{~V}$ (i.e. $z=1.5)$ \\
\hline Free board & $0.6 \mathrm{~m}$ for Q less than $10 \mathrm{~m}^{3} / \mathrm{s}$ and $0.75 \mathrm{~m}$ for Q more than $10 \mathrm{~m}^{3} / \mathrm{s}(\mathrm{IS} 10430: 2000)$ \\
\hline Cost of excavation & US\$ 10 per cubic meter of cut and $/ \mathrm{or}$ fill (cost in Iraq -2012$)$ \\
\hline Cost of lining & US\$250 per cubic meter of concrete (cost in Iraq - 2012) \\
\hline
\end{tabular}


length for lining and excavation of the channel is considered for purposes of comparison to depend on the determined crosssections and unit prices given in Table 2.

Plots of the unit cost of the channel against $b / d$ ratio in Fig. 1a-f reveal that the minimum cost corresponds to a $b / d$ ratio of about 0.40 . It can be also noted from the curves that the cost increases when the aspect ratio b/d increases. Another factor which plays an important role in the increase in cost is the bed slope, as can be observed from the curves in Fig. 1a-f.

The same conditions applied to the variables were
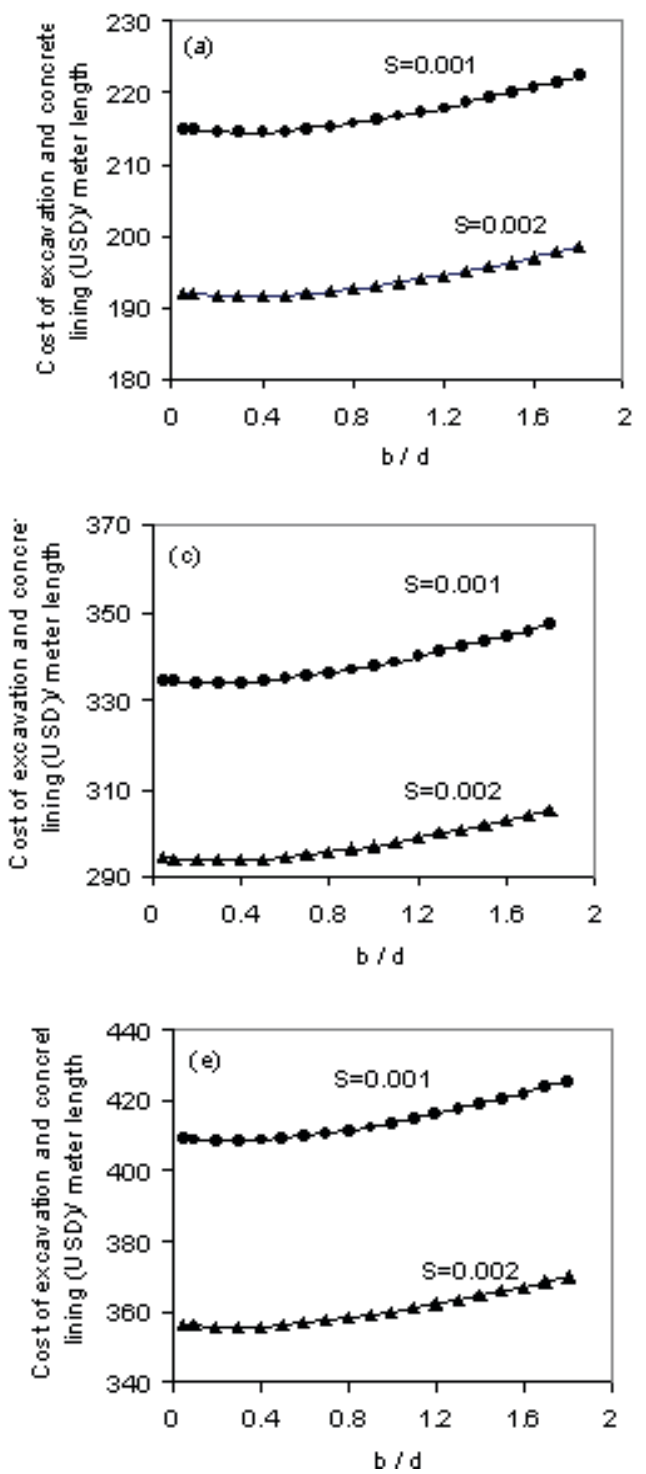

considered (i.e. same discharge, bed slope and side slope) to evaluate the recommended aspect ratio value according to formulae given by other researchers (Table 3). It has been noted that the aspect ratio is variable in most of the cases. This difference is noticed even when only one factor is taken into consideration, i.e., the side slope. Furthermore, similar differences have been noted in the CWC recommendations, where the discharge $Q$ is taken into consideration, and also in the case of Trout (1082) and Blackler and Guo (2009) where the cost ratio is considered.
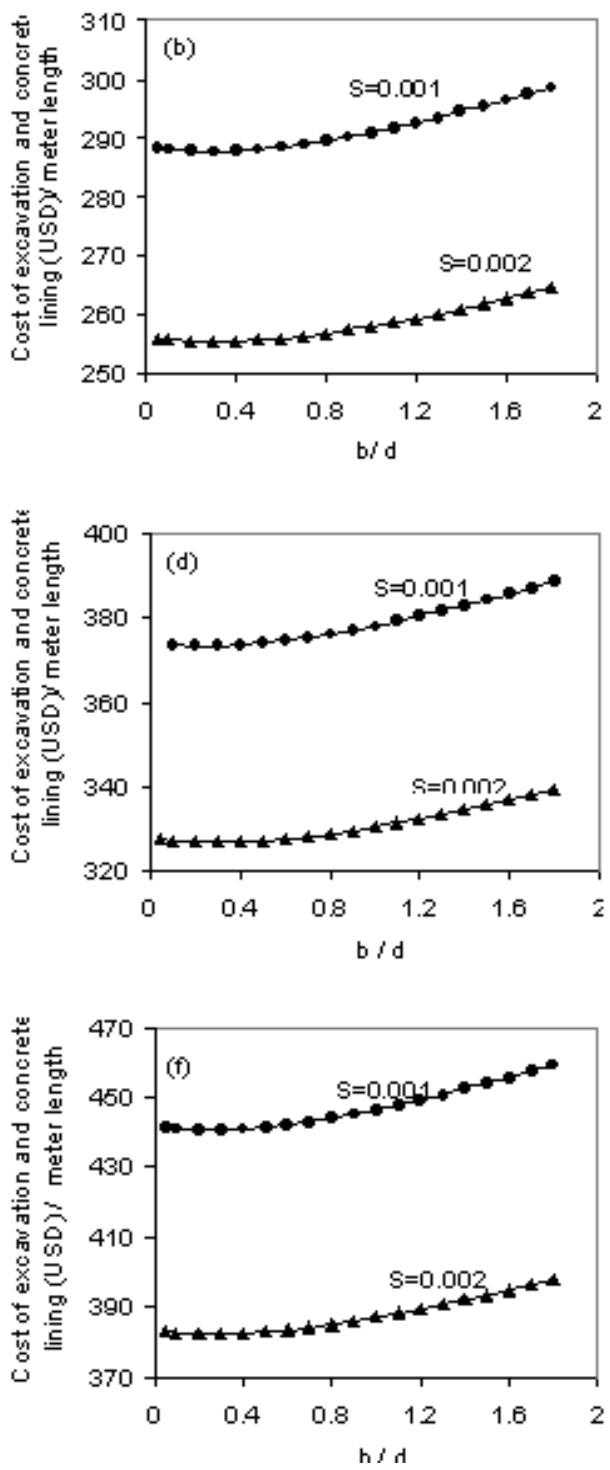

Figure 1

Cost of channel vs b/d for (a) $Q=5 \mathrm{~m}^{3} / \mathrm{s} ;$ (b) $Q=10 \mathrm{~m}^{3} / \mathrm{s}$; (c) $Q=15 \mathrm{~m}^{3} / \mathrm{s} ;$ (d) $Q=20 \mathrm{~m}^{3} / \mathrm{s}$; (e) $Q=25 \mathrm{~m}^{3} / \mathrm{s} ;$ (f) $Q=30 \mathrm{~m}^{3} / \mathrm{s}$

TABLE 3

Recommended $b / d$ ratio according to other authors

\begin{tabular}{|l|c|}
\hline Research (Eq.\#) & b/d ratio \\
\hline Guo and Hughes (Eq. 4) & 0.605 \\
\hline CWC (Table 1) & $4-8$ \\
\hline USBR (Eq. 6) & 2.5 \\
\hline Indian Engineers (Eq. 8) & 1.5 \\
\hline Trout (1982) (Eq. 10) & 0.606 \\
\hline
\end{tabular}




\section{Aspect ratio $(b / d)$ and/or depth $(d)$ as a function of $Q, V$, and $S$}

In order to study the relationship between the aspect ratio $(b / d)$ and water depth, along with other variables, such as discharge, velocity and bed slope of open channels, an Excel spreadsheet was developed for determining the dimensions of the cross-section corresponding to a known series of the other variables. In other words, a series of different channel cross-sections was designed after fixing the discharge, velocity, bed slope, and side slope values. The following procedures and assumptions have been adopted in this study:

- The flow in the channels is assumed to be steady and uniform.

- Continuity and Manning's equations are used as a base for the calculations.

- The channels are assumed to be concrete lined.

- The Manning roughness coefficient value for concrete is taken as 0.017 (Table 4).

- The cross-section of the channel is assumed to be trapezoidal.

- The side slope is fixed at $1.5 \mathrm{H}: 1.0 \mathrm{~V}$, taking into consideration the USBR recommendation in this regard (Chow, 1959).

In addition to the above assumptions, 6 different bed slopes are assumed for each case. These are: 0.002, 0.001, 0.0005, 0.00025, 0.0002 , and 0.00015 . Discharges are assumed to be within the range $0<Q \leq 50 \mathrm{~m}^{3} / \mathrm{s}$ with an incremental interval of $5 \mathrm{~m}^{3} / \mathrm{s}$. This discharge range was assumed based on the range of small hydropower channel discharges.

Various velocities are assumed to take the following values of $1,1.25,1.5,1.75,2,2.5$ and $3.0 \mathrm{~m} / \mathrm{s}$, as applicable. The minimum permissible velocity introduced by Chow (1959) was approximated it to $1 \mathrm{~m} / \mathrm{s}$, and the maximum permissible

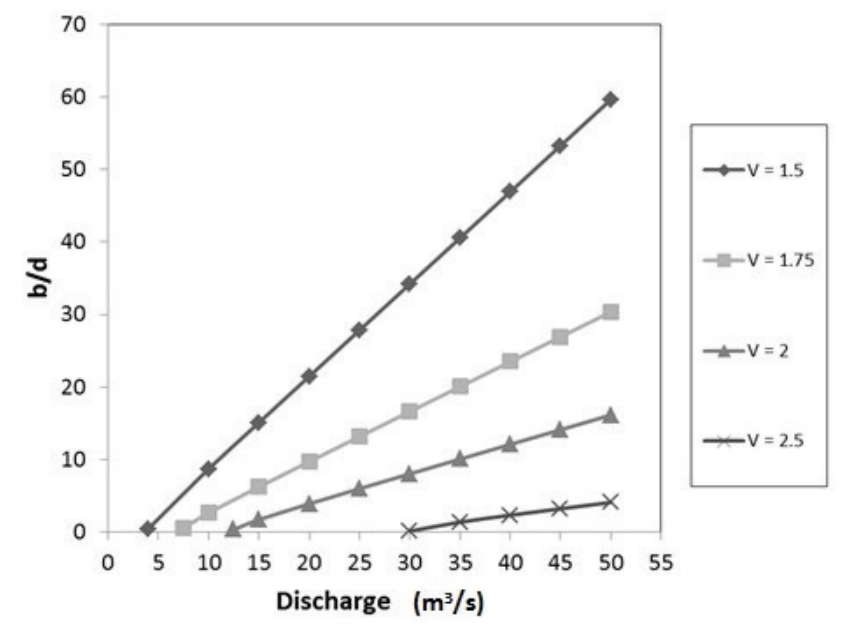

Figure 2

Discharge and $b / d$ when $S=0.001, z=1.5, n=0.017$ and for different velocities velocity for concrete lining of 2.7, recommended by IS 10430 (2000), was approximatedto $3 \mathrm{~m} / \mathrm{s}$. 225 channel cross-sections were used to develop the relations, based on the previously mentioned assumptions. In order to get the value of $d$ and $b / d$ for each of the previously mentioned cases, an Excel spreadsheet was developed to solve Eq. 2 along with the continuity equation, in an iterative manner.

From the relation between aspect ratio and discharge for different cases, it could be noted that the line in some cases intersects with the $X$-axis, $Q$ (Fig. 2). This means that in this specific case we cannot obtain the targeted values of velocity and bed slope. Accordingly, an envelope curve is developed to show the limitation of minimum possible discharges in each case by taking the intersection point of each individual case, as shown in Fig. 3. The envelope curve shown in Fig. 3 can be represented by an equation by making multiple regressions for the data. Thus the expression will be as follows:

$$
Q_{\min }=2.48 \times 10^{-5} \frac{V^{4.02}}{S^{1.48}}
$$

with correlation coefficient $R=0.998$.

Efforts were made to develop a formula that combines the relationships between the aspect ratio $b / d, Q, V$, and $S$. However, the formula found for this objective showed a poor correlation of $R=0.6$ compared to the results for other models. As an alternate choice, we find a correlation between $d, Q$, $V$, and $S$. In order to obtain this correlation, an expression is targeted as a multiple regression formula for the data using an Excel spreadsheet and Neural Power software, which is a general, integrated, and powerful artificial neural network (ANN) program. The results of this work were as follows:

$$
d=1.21 \times 10^{-3} \frac{V^{1.858}}{Q^{0.116} S^{0.884}}
$$

with correlation coefficient $R=0.99$.

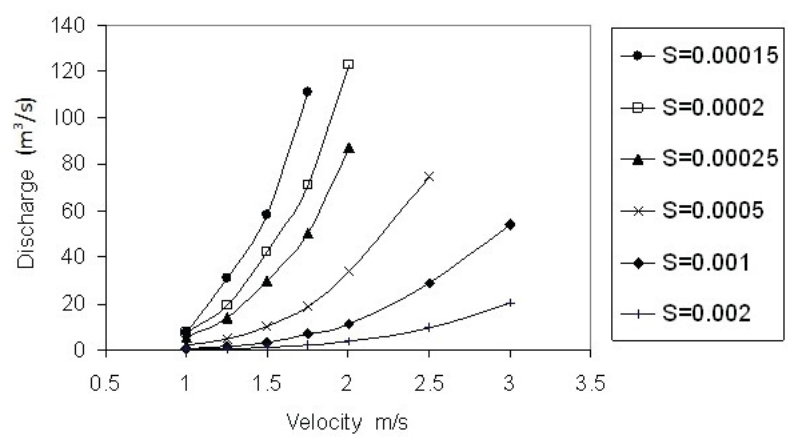

Figure 3

Minimum possible discharge for specific bed slope and velocity

\begin{tabular}{|l|l|c|c|c|}
\hline \multicolumn{5}{|c|}{ Manning roughness coefficients in rigid-boundary for open channels (Chin, 2006) } \\
\hline \multirow{2}{*}{ Type } & Characteristics & $\begin{array}{c}\text { Minimum } \\
\boldsymbol{n}\end{array}$ & $\begin{array}{c}\text { Normal } \\
\boldsymbol{n}\end{array}$ & Maximum $\boldsymbol{n}$ \\
\hline \multirow{3}{*}{ Concrete } & $\begin{array}{l}\text { Finished with gravel on } \\
\text { bottom }\end{array}$ & 0.015 & 0.017 & 0.020 \\
\cline { 2 - 5 } & Unfinished & 0.014 & 0.017 & 0.020 \\
\hline
\end{tabular}


In Eq. 14, the only difficulty may be the assumption of the value of velocity. For this purpose, in all of the cases the corresponding section for maximum velocity for each discharge (which corresponds to the smallest cross-section) and within a specific bed slope has been extracted from the main data (design of sections). Consequently, through a multiple regression analysis, the following equation is derived:

$$
V_{\max }=12.63 Q^{0.24} S^{0.36}
$$

with correlation coefficient $R=0.98$.

To get the optimal depth (Eq. 16) based on the maximum possible velocity, Eq. 15 is substituted into Eq. 14:

$$
d_{\mathrm{opt}}=0.135 \frac{Q^{0.334}}{S^{0.215}}
$$

where: $d_{\text {opt }}$ is the optimal depth of water. The bed width can be obtained from the continuity equation.

\section{Linear genetic programming for obtaining $b / d$ as a function of $Q$ and $S$}

Linear genetic programming (LGP) is an extension of conventional genetic programming, first introduced by Brameier and Banzhaf (2001). The term 'linear' refers to the representation of the computer programs, but a LGP chromosome (program) contains highly non-linear functions. The most significant strength of LGP is that it evolves computer programs very quickly by running directly on the computer processor in a low-level language (like C or C++) (Oltean and Grosan, 2003). An excerpt from a LGP program can be, for example:

$$
\begin{aligned}
& r[0]+=0.94 \\
& r[0] /=v[1] \\
& r[1]+=r[0] \\
& r[0]^{*}=r[1] \\
& r[0]+=v[2]
\end{aligned}
$$

where: $\mathrm{v}[i]$ represents the input variables, $\mathrm{r}[1]$ is the temporary computation variable, the output of which is the value remaining in $r[0]$ after the program executes.

A brief algorithm for the LGP technique can be given as follows (Brameier, 2004):

- Step (i): Initialize a population of candidate programs randomly (size of population and program is pre-set).
- Step (ii): Pick 4 programs randomly (tournament selection) out of the population programs. Compare these 4 programs based on fitness function and pick 2 winners.

- Step (iii): Apply the search operators (mutation and crossover) to the winners and produce two 'offspring' as follows: - Cross-over the 2 winners with cross-over frequency - Mutate each winner program with mutation frequency

- Step (iv): Replace 2 losers in the tournament with the winner offspring generated in step (iii).

- Step (v): Repeat from step (ii) to step (iv) until the run is terminated (goal is reached).

- Step (vi): Finally, convert the best program of the welltrained LGP into a functional representation by successive replacements of $v[i]$ starting with the last effective instruction (optimizing and simplifying the best program).

Further information on the LGP technique can be acquired from Brameier (2004) and Oltean and Grosan (2003). A limited number of LGP applications in water engineering have been recorded by Guven (2009), Guven and Kisi (2011), and Traore and Guven (2011).

In this section LGP is used to model the relation between the aspect ratio, $Q$ and $S$. The velocity is assumed to be the maximum probable value obtained from Eq. 15. Another group of cross-sections was designed for the same range of discharges $\left(0<Q \leq 50 \mathrm{~m}^{3} / \mathrm{s}\right)$ and with the same six different bed slopes, by fixing the side slope at $z=1.5$, and Manning coefficient at $n=0.017$, obtained from Table 4 . The total number of newly designed cross-sections was 60 .

Out of the total number of 60 input-output sets $(Q, S, b / d)$, 40 sets (66\%) were used in training and the remaining 20 (33\%) were reserved for validation purposes. The function set of a LGP system is composed of arithmetic operators $\left(+,-, /,{ }^{*}\right)$ and functions (ex, xa, cos, sin, tan, log, sqrt). In this study, after several runs, the functional set and operational parameters given in Table 5 were found to give the best results. The fitness of LGP individuals is computed by using the mean square error (MSE). The maximum size of LGP programs was limited to 64 instructions per program. These configurations were evaluated for each corresponding LGP model and were experienced as sufficient. After the MSE between the predicted and observed values for the training stage of each LGP program reached an unchanged minimum (generally lower than 0.5), the training of LGP was stopped. Each trained LGP program was converted into a simplified functional form as shown in Eq. 17:

\begin{tabular}{|l|c|}
\hline \multicolumn{2}{|c|}{ TABLE 5 } \\
\hline Description of parameter & \multicolumn{1}{|c|}{ Setting of parameter } \\
\hline Function set & $+,-,{ }^{*}, /$,, power \\
\hline Population size & 250 \\
\hline Mutation frequency $\%$ & 95 \\
\hline Crossover frequency $\%$ & 50 \\
\hline Number of replication & 10 \\
\hline Block mutation rate $\%$ & 30 \\
\hline Instruction mutation rate $\%$ & 30 \\
\hline Instruction data mutation rate $\%$ & 40 \\
\hline Homologous crossover $\%$ & \multicolumn{2}{|c|}{95} \\
\hline Program size & initial 16, maximum 64 \\
\hline
\end{tabular}




$$
b / d=0.669 Q^{1 / 8}+2.66(Q S)^{1 / 4}
$$

with correlation coefficient $R=0.990$ and MSE $=0.001$ (Fig. 4). Eq. 17 looks like a simple regression equation although it is the final simplified representation of the prementioned complex LGP modelling. Also the Nash-Sutcliffe model efficiency applied to Eq. 17 and the obtained efficiency coefficient of 0.989 revealed a near-perfect match of modelled data (Nash and Sutcliffe, 1970).

\section{Application in case study}

In order to evaluate the application of the new equation (Eqs 16 and 17), the properties of 10 existing channels were obtained (Table 6). The existing channels have been redesigned using Eqs 16 and 17 (Table 6). The total cost of lining and excavation

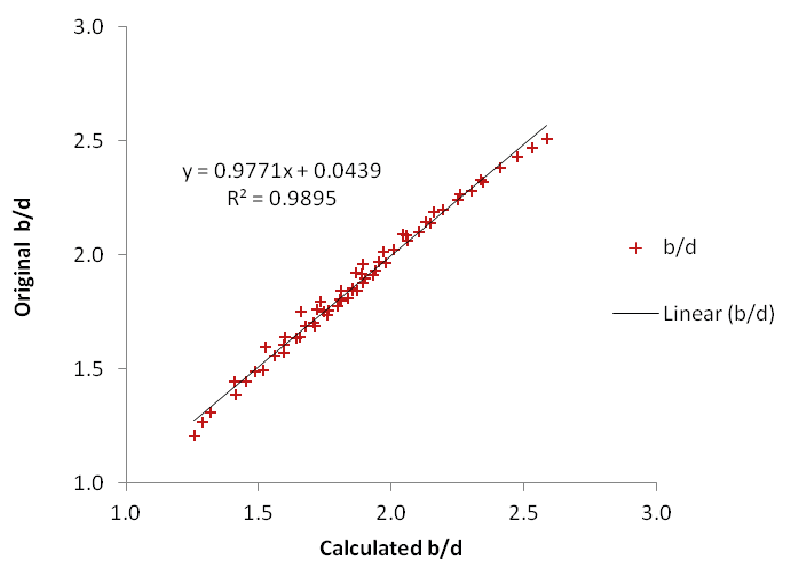

Figure 4

Comparison between original and calculated (b/d) from Eq. 17 per unit length has been calculated for both cases (existing and new design) based on the same unit price mentioned in Table 2. Table 7 shows a comparison between the total cost in both cases (existing and proposed design). It can be noted from Fig. 5 that in almost all cases the proposed design cost is less than the existing one. Nevertheless the equation is applicable to cases where the discharges exceed the discharge range used in deriving the new equations (i.e. $0<Q \leq 50 \mathrm{~m}^{3} / \mathrm{s}$ ).

\section{CONCLUSION}

This study presented a semi-theoretical approach coupled with the linear genetic programming (LGP) technique, which predicts the optimal depth and the aspect ratio b/d of

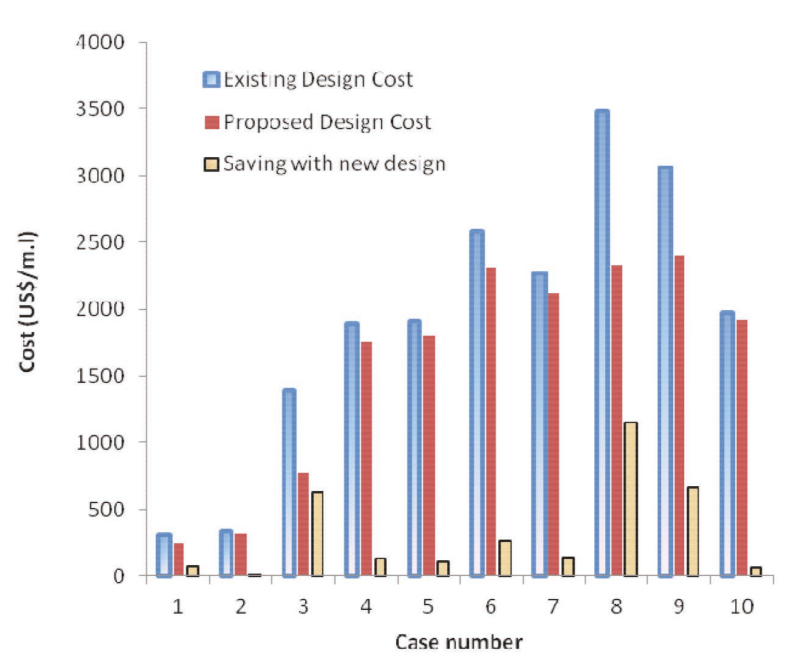

Figure 5

Cost comparison between the existing design and the proposed design of the channels

\begin{tabular}{|c|c|c|c|c|c|c|c|c|c|c|}
\hline \multicolumn{11}{|c|}{$\begin{array}{c}\text { TABLE } 6 \\
\text { Properties of existing channels used as case studies and dimension for proposed design }\end{array}$} \\
\hline \multirow{2}{*}{ No. } & \multirow{2}{*}{ Name of channel } & \multirow{2}{*}{$\begin{array}{l}\text { Region } \\
\text { (country) }\end{array}$} & \multirow{2}{*}{$Q\left(\mathrm{~m}^{3} / \mathrm{s}\right)$} & \multirow[t]{2}{*}{$\mathbf{S}$} & \multirow{2}{*}{$\underset{(H / V)}{z}$} & \multicolumn{2}{|c|}{$\begin{array}{l}\text { Existing } \\
\text { channel } \\
\text { dimension }\end{array}$} & \multicolumn{3}{|c|}{$\begin{array}{l}\text { Proposed design } \\
\text { dimension* }\end{array}$} \\
\hline & & & & & & $\begin{array}{l}\text { b } \\
(\mathbf{m})\end{array}$ & $d(m)$ & $b / d$ & $d(\mathbf{m})$ & $b(\mathbf{m})$ \\
\hline 1 & Yakacık HPP & Hatay (Turkey) & 5.30 & 0.00020 & 1.5 & 1.60 & 2.00 & 1.3 & 1.47 & 1.91 \\
\hline 2 & Kozak HPP & $\begin{array}{l}\text { Ceyhan Basin } \\
\text { (Turkey) }\end{array}$ & 15.00 & 0.00050 & 1.5 & 2.50 & 1.90 & 1.72 & 1.71 & 2.94 \\
\hline 3 & Manniaru Canal & Tamilnadu (India) & 43.20 & 0.00014 & 1.5 & 30.48 & 1.52 & 1.81 & 3.20 & 5.79 \\
\hline 4 & Bhakra Canal & Haryana (India) & 192.00 & 0.00017 & 1.5 & 12.30 & 5.40 & 2.42 & 5.05 & 12.22 \\
\hline 5 & Yamuna Power Canal & $\begin{array}{l}\text { Uttar Pradesh } \\
\text { (India) }\end{array}$ & 198.00 & 0.00017 & 1.5 & 10.98 & 5.71 & 2.44 & 5.11 & 12.47 \\
\hline 6 & Mahi Right Bank Canal & Gujarat (India) & 198.10 & 0.00007 & 1.5 & 16.46 & 6.23 & 2.21 & 6.18 & 13.66 \\
\hline 7 & $\begin{array}{l}\text { Satluj Yamuna Link } \\
\text { Canal }\end{array}$ & Punjab (India) & 212.00 & 0.00011 & 1.5 & 14.02 & 5.99 & 2.35 & 5.74 & 13.49 \\
\hline 8 & Lower Ganga Canal & $\begin{array}{l}\text { Uttar Pradesh } \\
\text { (India) }\end{array}$ & 213.00 & 0.00008 & 1.5 & 51.45 & 3.36 & 2.27 & 6.15 & 13.96 \\
\hline 9 & Westren Kosl Canal & Bihar (India) & 236.70 & 0.00009 & 1.5 & 35.06 & 4.33 & 2.34 & 6.21 & 14.53 \\
\hline 10 & $\begin{array}{l}\text { Sunder Nagar Hydel } \\
\text { Canal }\end{array}$ & Himachal (India) & 240.69 & 0.00021 & 1.5 & 9.45 & 6.26 & 2.59 & 5.21 & 13.49 \\
\hline
\end{tabular}

${ }^{*}$ Note: (b/d) from Eq. 17 and (d) from Eq. 16. 
TABLE 7

Total cost of lining and excavation (USD / unit length)

\begin{tabular}{|l|l|c|c|}
\hline$\#$ & Name of channel & Existing design cost (USD/m) & Proposed design cost (USD/m) \\
\hline 1 & Yakacik HPP & 312.25 & 240.74 \\
\hline 2 & Kozak HPP & 335.45 & 321.78 \\
\hline 3 & Manniaru Canal & 1398.65 & 772.07 \\
\hline 4 & Bhakra Canal & 1895.85 & 1760.35 \\
\hline 5 & Yamuna Power Canal & 1904.70 & 1801.26 \\
\hline 6 & Mahi Right Bank Canal & 2580.70 & 2315.63 \\
\hline 7 & Satluj Yamuna Link Canal & 2268.50 & 2123.19 \\
\hline 8 & Lower Ganga Canal & 3483.75 & 2329.23 \\
\hline 9 & Westren Kosl Canal & 3066.05 & 2403.78 \\
\hline 10 & Sunder Nagar Hydel Canal & 1979.90 & 1916.86 \\
\hline
\end{tabular}

concrete-lined channels, provided that the discharge $Q$ and the bed slope $S$ are known. The side slope and Manning coefficient were assumed as $z=1.5$ and $n=0.017$, respectively.

The proposed model automatically designs the most economical trapezoidal cross-section for a concrete lined channel under maximum permissible velocity. Equation 15 gives the maximum permissible velocity which is thereafter used in Eq. 14 to get the optimal depth of flow (Eq. 16). The bed width $b$ is occasionally obtained from the continuity equation.

The model defines a minimum possible discharge for a specific bed slope and fixed velocity through Eq. 13. For discharges from $5-30 \mathrm{~m}^{3} / \mathrm{s}$, it is found that the cost of the concrete-lined channel will be minimal when the value of the aspect ratio, $b / d$, is approx. 0.40. In addition, it was observed that the lower the value of the aspect ratio, the lower the cost of the lining process. The cost of the channel for the same discharge was found to be lower for greater bed slopes.

The recommended aspect ratios given in the literature can be used within limits, as these ratios are not applicable to all conditions, because sometimes they result in velocities greater than maximum permissible velocity. The present semitheoretical model can be used as a superior alternative to the conventional methods. The proposed LGP model is superior to so-called black-box artificial intelligence techniques, due to its practical and xplicit formula (Eq. 17), which can be used even by non-specialist users.

Through the case studies it was found that the new equations are applicable even for discharges exceeding $50 \mathrm{~m}^{3} / \mathrm{s}$.

\section{REFERENCES}

ARSHAD M, AHMAD N, USMAN M and SHABBIR A (2009) Comparison of water losses between unlined and lined watercourse in Indus Basin of Pakistan. Pak. J. Agric. Sci. 46 (4) 280-284.

BLACKLER GE and GUO CY (2009) Least-cost and most efficient channel cross sections. J. Irrig. Drain. Eng. 135 (2) 248-251.

BRAMEIER M (2004) On Linear Genetic Programming. PhD thesis,

University of Dortmund.

BRAMEIER M and BANZHAF W (2001) A comparison of linear genetic programming and neural networks in medical data mining. IEEE Trans. Evol. Comput. 5 (1) 17-26.

CHIN DA (2006) Water Resources Engineering. Pearson Education Inc., New Jersey.

CHOW VT (1959) Open Channel Hydraulics. McGraw-Hill, New York. FRENCH RH (1986) Open Channel Hydraulics. McGraw-Hill, Singapore.

GHAZAW YM (2011) Design and analysis of a canal section for minimum water loss. Alexandria Eng. J. 50 (4) 337-344.

GHAZAW Y, SALEM AAS and KHAIRy O (2000) Minimum-cost canal cross section. Alexandria Eng. J. 39 (1) 97-104.

GHUMMAN AR, KHAN RA, KHAN QUZ and KHAN Z (2012) Modeling for various options of a canal system. Water Resour. Manage. 26 (8) 2383v2392.

GUO CY and HUGHES WC (1984) Optimal channel cross section with freeboard. J. Irrig. Drain. Eng. 110 (3) 304-314.

GUVEN A (2009) Linear genetic programming for time-series modeling of daily flow rate. Earth Syst. Sci. 118 (1) 37-146.

GUVEN A and KISI O (2011) Daily pan evaporation modeling using linear genetic programming technique. Irrig. Sci. 29 (2) 135-145.

IS 10430:2000 Indian Standard. Criteria for design of lined canals and guidance for selection of type of lining. Bureau of Indian Standards, New Delhi.

MOGHAZI H and ISMAIL ES (1996) A study of losses from field channels under arid region conditions. Irrig. Sci. 17(3) 105-110.

MONADJEMI P (1994) General formulation of best hydraulic channel section. J. Irrig. Drain. Eng. 120 (1) 27-35.

NASH JE and SUTCLIFFE JV (1970) River flow forecasting through conceptual models Part I - A discussion of principles. J. Hydrol. 10 (3) 282-290.

OLTEAN M and GROSAN C (2003) A comparison of several linear genetic programming techniques. Complex Syst. 14 (1) 1-29.

SUBRAMANYA K (1986) Flow in Open Channels. TATA McGraw Hill, New Delhi.

SWAMEE PR, MISHRA GC and CHAHAR BR (2000). Minimum cost design of lined canal section. Water Resour. Manage. 14 (1) 1-12.

SWAMEE PR, MISHRA GC and CHAHAR BR (2002) Optimal design of transmission canal. J. Irrig. Drain. Eng. 128 (4) 234-243.

TRAORE S and GUVEN A (2011) New algebraic formulations of evapotranspiration extracted from gene-expression programming in the tropical seasonally dry regions of West Africa. Irrig. Sci. 31 (1) 1-10.

TROUT TJ (1982) Channel design to minimize lining material costs. J. Irrig. Drain. Eng. 108 (4) 242-249. 